\title{
Comparison of Demographic and Diagnostic Characteristics of Iranian Inpatients With Bipolar I Disorder to Western Counterparts
}

\author{
Atefeh Ghanbari Jolfaei ${ }^{1,} ;$ Pari Ghadamgahi ${ }^{2}$; Masoud Ahmadzad-Asl ${ }^{3}$; Amir Shabani ${ }^{4}$ \\ ${ }^{1}$ Department of Psychiatry, Minimally Invasive Surgery Research Center, Iran University of Medical Sciences, Tehran, IR Iran \\ ${ }_{2}^{2}$ Minimally Invasive Surgery Research Center, Iran University of Medical Sciences, Tehran, IR Iran \\ ${ }_{3}^{3}$ Mental Health Research Center, Tehran Institute of Psychiatry, School of Behavioral Sciences and Mental Health, Iran University of Medical Sciences, Tehran, IR Iran \\ ${ }^{4}$ Mental Health Research Center, Iran University of Medical Sciences, Tehran, IR Iran \\ *Corresponding author: Atefeh Ghanbari Jolfaei, Department of Psychiatry, Minimally Invasive Surgery Research Center, Iran University of Medical Sciences, Tehran, IR Iran. \\ Tel: +98-2164352376, Fax: +98-2166506853, E-mail: draghj@yahoo.com
}

Received: October 11, 2013; Revised: February 6, 2014; Accepted: April 25, 2014

\begin{abstract}
Background: Patients' characteristics influence the disorders outcome, so it is valuable to compare mood disorders and inpatients' attributes in different large samples.

Objectives: This study was designed to assess demographic and diagnostic characteristics of 3000 Iranian inpatient with bipolar disorders.

Patients and Methods: We collected the information of demographic, clinical, and therapeutic characteristics of the patients who were hospitalized in Iran Hospital of Psychiatry, a university affiliated hospital in Tehran, during the 5 years from 2006 to 2011.

Results: About $66.1 \%$ of the subjects were males and $33.9 \%$ were females. Iranian patients are characterized by a higher rate of unemployment, being more single, having health insurance and lower rate of divorce and education compared to the other clinical samples. In the majority of the patients, the disorder had begun with manic phase.

Conclusions: Clinical and therapeutic features of Iranian patients are different from patients in western countries.
\end{abstract}

Keywords: Bipolar I Disorder; Demographic Survey; Diagnostic Characteristics

\section{Background}

Mood disorders, including unipolar and bipolar disorders, are the most frequent psychiatric disorders both in the clinical settings and community. According to the previous studies, the lifetime prevalence rate of major depressive disorder was between $4.9 \%$ and $20 \%$ and the lifetime prevalence rates of bipolar I and II disorders have been reported to be between 1.3\% and 3.9\% (1).

Bipolar disorders are associated with serious complications such as increased risk of other psychiatric Axis I and II comorbidities, especially alcohol and substance use disorders, and increased rates of somatic morbidity and mortality. They also have disruptive effects on quality of life, productivity and daily functioning (1-12). Besides, bipolar disorders are associated with high risk of both completed and attempted suicide (13-15).

In the Global Burden of Disease Study, bipolar disorder was ranked as the eighth leading cause of medical disability worldwide (16). Furthermore, a majority of bipolar patients were reported to suffer from high relapse rates even during mood stabilizer treatments (17). These features lead to burnout in family and have hazardous effects on society (5-17).

As patients' characteristics influence the disorders out- come (18), it is valuable to investigate mood disorders in patients of different large samples, and compare their properties with features. There are articles that reported demographic and clinical features of these patients in the western countries (8-12, 18-23), but in Iran we have limited data in this regard. According to some studies, the course of mood disorders is somehow different in Iranian patients. For instance, unlike other studies, in the majority of Iranian bipolar patients, the disorder begins with manic phase. This confirms the need for further researches in order to gather more information $(24,25)$.

\section{Objectives}

This study was designed to assess demographic and diagnostic characteristics of 3000 Iranian inpatients with bipolar disorders in a psychiatric hospital.

\section{Materials and Methods}

In this retrospective cross-sectional study, we collected the files information of inpatients hospitalized from 2006 to 2011, Iran Hospital of Psychiatry, a university affiliated hospital in Tehran, Iran. The hospital is located

Copyright (C) 2015, Mazandaran University of Medical Sciences. This is an open-access article distributed under the terms of the Creative Commons Attribution-NonCommercial 4.0 International License (http://creativecommons.org/licenses/by-nc/4.0/) which permits copy and redistribute the material just in noncommercial usages, provided the original work is properly cited. 
$7 \mathrm{~km}$ out of Tehran (Karaj road). It offers inpatient and outpatient services to all clients from all over the country, especially the west of Tehran. It has 130 beds, 1 emergency department with 22 beds, 3 wards for men with 90 beds and 1 ward for women with 30 beds. Bed occupancy of this hospital is about $100 \%$.

The patients diagnosed as bipolar disorders in first hospitalization by expert psychiatrists (faculties of Iran University of Medical Sciences) were enrolled in the study. Diagnosis was made based on the 4th edition of Diagnostic and Statistical Manual of Mental Disorders (DSM-TV-TR) criteria and through unstructured interviews.

A total of 3000 patients with diagnosis of bipolar I disorder were hospitalized in Iran Hospital during the mentioned time. Demographic, clinical, and therapeutic characteristic of the patients including age, gender, date and place of birth, home address, marital status, number of children, occupational status, educational status, insurance status, age of first episode, age of first hospitalization, type of first episode, number of hospitalizations, duration of each hospitalization, psychiatric diagnosis during each hospitalization, type of treatments (medical treatments, electroconvulsive therapy) during each hospitalization were collected by checking their hospital files. Data investigation took 6 months.

Data analysis was performed with SPSS for Windows (version 21.0, SPSS Inc., Chicago, IL, USA) and we used descriptive statistics for quantitatively describing the features. This study was approved by the Ethical Committee of Psychiatric Department of Iran University of Medical Sciences and confidential records were kept at a secure area with limited access, and stripping them of identifying information was considered.

\section{Results}

About $66.1 \%$ of subjects were men and $33.9 \%$ were women. The majority of the patients was unemployed and had lower than high-school degrees. Demographic characteristics and clinical features are presented in Table 1.

\section{Discussion}

In this study, the age of disease onset was $27.9 \pm 0.19$ $\mathrm{y}$ and age of their first hospitalization was $32.5 \pm 0.2 \mathrm{y}$. Men were admitted more than women in the hospital. Less than half of inpatients with BID (Bipolar I Disorder) were married. Low educational level and high health insurance coverage and unemployment rate among them were considerable.

In Kupfer et al. study, 64.5 out of 3000 bipolar patients were women, and the mean age of onset was 19.8 years. Over 60\% completed college and 64\% were currently unemployed (23). In Iran Hospital, the number of men beds was triple of women beds and this was the reason why the majority of our patients were men.

The data of this study were compared to Suppes et al. (26), Lish et al. (27), Regier et al. (28) and Kogan et al. studies data (18) (Table 2). Our results are in conflict with western studies in a number of features, many of them may reflect cultural and society differences. As it is presented in Table 2, the Iranian patients are characterized by a higher rate of unemployment, being single, having health insurance and lower rate of divorce and education compared to the other clinical samples.

Table 1. Demographic Characteristics and Clinical Features of Bipolar I Patients ${ }^{\text {a }}$

\begin{tabular}{|c|c|}
\hline Variable & Value \\
\hline Total & 3000 \\
\hline Age at onset; $y$ & $27.9 \pm 0.19$ \\
\hline Age at first admission; $y$ & $32.5 \pm 0.2$ \\
\hline \multicolumn{2}{|l|}{ Gender } \\
\hline Male & $1984(66.1)$ \\
\hline Female & $1016(33.9)$ \\
\hline \multicolumn{2}{|l|}{ Marital Status } \\
\hline Married & $1414(47.1)$ \\
\hline Single & $1258(41.9)$ \\
\hline Divorced & $328(10.9)$ \\
\hline \multicolumn{2}{|l|}{ Education degree } \\
\hline Illiterate & $173(5.8)$ \\
\hline Under diploma & $1747(58.2)$ \\
\hline Diploma & $828(27.6)$ \\
\hline University degree & $252(8.4)$ \\
\hline Had health insurance & $2778(92.6)$ \\
\hline \multicolumn{2}{|l|}{ Occupation status } \\
\hline Clerk & $139(4.6)$ \\
\hline Worker & $346(11.5)$ \\
\hline Self-employed & $361(12)$ \\
\hline Retired & $67(2.2)$ \\
\hline Unemployed & $1433(47.6)$ \\
\hline Housewife & $654(21.8)$ \\
\hline Admission No & $2.39 \pm 0.04$ \\
\hline Mean duration at admission, $d$ & $32.1 \pm 0.21$ \\
\hline Number of admission with ECT ${ }^{b}$ & $0.39 \pm 0.01$ \\
\hline \multicolumn{2}{|l|}{ Index episode } \\
\hline Mania & $1953(65.1)$ \\
\hline Depressive & $910(30.3)$ \\
\hline Mixed & $81(2.7)$ \\
\hline Others & $56(1.9)$ \\
\hline
\end{tabular}


Ghanbari Jolfaei A et al.

\begin{tabular}{|c|c|c|c|c|c|}
\hline Variable & The present study & Suppes et al.(26) & Lish et al. (27) & Regier et al. (28) & Kogan et al. (18) \\
\hline Sample size & 3000 & 261 bipolar disorders, 216 BID & 500 & 20000 & 1000 \\
\hline Age at onset; $y$ & $27.9 \pm 0.19$ & $22.16 \pm 9.6$ & & & $17.4 \pm 8.6$ \\
\hline Age at first admission; $y$ & $32.5 \pm 0.2$ & $29.46 \pm 10.7$ & & & \\
\hline \multicolumn{6}{|l|}{ Gender } \\
\hline Female & 33.9 & 56 & 63 & 57 & 58.6 \\
\hline \multicolumn{6}{|l|}{ Marital status } \\
\hline Married & 47.1 & 43 & 46 & 44 & 36.2 \\
\hline Single & 41.9 & 31 & 25 & 22 & 35.2 \\
\hline Divorced & 10.9 & 24 & 28 & 15 & 23.5 \\
\hline \multicolumn{6}{|l|}{ Educational level } \\
\hline Illiterate & 5.8 & & & & \\
\hline Under diploma & 58.2 & & & & \\
\hline Diploma & 27.6 & & 5 & 22.7 & 13.8 \\
\hline University & 8.4 & & 55 & 28.6 & 82.3 \\
\hline \multicolumn{6}{|l|}{ Health insurance status } \\
\hline No health insurance & 7.4 & 14 & & & \\
\hline \multicolumn{6}{|l|}{ Employment status } \\
\hline Unemployed & 47.6 & 6 & & & 22.0 \\
\hline \multicolumn{6}{|l|}{ Index episode } \\
\hline Mania & 65 & & & & 26.1 \\
\hline Depressive & 30.3 & 25 & & & 52.0 \\
\hline Mixed & 2.7 & 48 & & & 21.0 \\
\hline Others & 1.9 & & & & 0.9 \\
\hline
\end{tabular}

${ }^{\mathrm{a}}$ Data are presented as Mean $\pm \mathrm{SD}$, or (\%).

High rates of unemployment, lower education and being single perhaps are due to the stigma and insufficient social resources for patients with mental disorders in Iran. Also, it could be due to the higher prevalence of these attributes in the Iranian general population than western populations. Furthermore, Iran Hospital is located in a low socioeconomic region, outside of Tehran and the economic and educational properties of the patients of this study could not be generalized to all the psychiatric inpatients of Iran.

Age of onset and the first admission were also higher than those of other studies. Overlooking the symptoms of mania, lack of insight into manic symptoms, and recall bias could be the reasons of higher age of onset. In addition, misdiagnoses and the stigma as a barrier to on time hospitalization may be the causes of higher age of first admission.

In the majority of the patients, the disorder had begun with manic phase $(24,25)$, which is consistent with the data of previous Iranian studies on bipolar patients and in contrast to studies in western countries. Some reasons such as more acceptability and tolerability of depressive symptoms rather than behaviorally disruptive manic epi- sodes or overlooking of depressive symptoms by mental health system professionals, patients, and their families could perhaps justify these results. Bed occupancy is high in Iran Hospital. Hence, it is possible that patients with mild form of disease, especially depressed patients have not been admitted regarding the hospital priority for admitting aggressive manic patients. Depression was higher in the women and the number of female beds was one third of male beds. So it can be another reason that mania was the prominent feature of the disorder. Furthermore, all the other studies were carried out on outpatients and this could be another explanation for differences of types of episodes. According to Jablensky study on severely ill hospitalized patients in Germany, (100 years ago) most "index" episodes were mania (29).

In a study on hospitalized bipolar patients in Finland, the corresponding peak of 1-year incidences for a bipolar depressive episode occurred at the same age, was about half of that reported for mania (30). On the other hand, in a study carried out on 8,889 psychiatric inpatients, 52.1 out of 1938 bipolar patients were men and almost $50 \%$ of patients were in depressed episode (31). It seems that the findings in the literature are conflicting and difficult to 
reconcile, so it is highly recommended to design more studies aiming to investigate probable etiologies such as genetics.

Rate of health insurance shows the better medical insurance coverage in Iran than western countries; however long waiting lists of state-run hospitals, increasing healthcare costs and poor insurance coverage of private outpatients' services should not be disregarded.

Retrospective method and lack of a standard diagnostic instrument were the limitations of this study. In addition, this study was conducted based on the data from medical records of inpatients and lacked appropriate assurance of quality and consistency of collected data. However, considering that the hospital was a university affiliated residency training center and the diagnosis was based on DSM-IV-TR criteria, authors would assume acceptable requirements for using those findings. It is highly recommended to design future outpatient studies in order to review clinical features of bipolar outpatients and compare them with studies in other countries.

\section{Acknowledgements}

Authors really appreciate the kindness and assistance of all psychiatrists, residents, and staff of Iran Hospital of Psychiatry, Tehran, IR Iran.

\section{Authors' Contributions}

Atefeh Ghanbari Jolfaei and Amir Shabani conceived and designed the evaluation. Pari Ghadamgahi collected the clinical data. Atefeh Ghanbari Jolfaei interpreted the clinical data and Masoud Ahmadzad-Asl performed the statistical analysis. Atefeh Ghanbari Jolfaei drafted the manuscript. All authors read and approved the final manuscript.

\section{Declaration of Interest}

None declared.

\section{References}

1. Kessler RC, Berglund P, Demler O, Jin R, Merikangas KR, Walters EE. Lifetime prevalence and age-of-onset distributions of DSM-IV disorders in the National Comorbidity Survey Replication. Arch Gen Psychiatry. 2005;62(6):593-602.

2. Judd LL, Akiskal HS. The prevalence and disability of bipolar spectrum disorders in the US population: re-analysis of the ECA database taking into account subthreshold cases. J Affect Disord. 2003;73(1-2):123-31.

3. Kessler RC, McGonagle KA, Zhao S, Nelson CB, Hughes M, Eshleman S, et al. Lifetime and 12-month prevalence of DSM-III-R psychiatric disorders in the United States. Results from the National Comorbidity Survey. Arch Gen Psychiatry. 1994;51(1):8-19.

4. Kessler RC, Rubinow DR, Holmes C, Abelson JM, Zhao S. The epidemiology of DSM-III-R bipolar I disorder in a general population survey. Psychol Med.1997;27(5):1079-89.

5. Kessler RC, Zhao S, Blazer DG, Swartz M. Prevalence, correlates, and course of minor depression and major depression in the $\mathrm{Na}-$ tional Comorbidity Survey. J Affect Disord. 1997;45(1-2):19-30.

6. Lepine JP, Gastpar M, Mendlewicz J, Tylee A. Depression in the community: the first pan-European study DEPRES (Depression Research in European Society). Int Clin Psychopharmacol. 1997;12(1):19-29.
7. Wittchen HU, Hofler M, Meister W. Prevalence and recognition of depressive syndromes in German primary care settings: poorly recognized and treated? Int Clin Psychopharmacol. 2001;16(3):121-35.

8. Weissman MM, Leaf PJ, Tischler GL, Blazer DG, Karno M, Bruce ML, et al. Affective disorders in five United States communities. Psychol Med.1988;18(1):141-53.

9. Weissman MM, Bland RC, Canino GJ, Faravelli C, Greenwald S, Hwu HG, et al. Cross-national epidemiology of major depression and bipolar disorder. JAMA. 1996;276(4):293-9.

10. Wilhelm K, Mitchell P, Slade T, Brownhill S, Andrews G. Prevalence and correlates of DSM-IV major depression in an Australian national survey. J Affect Disord. 2003;75(2):155-62.

11. Stewart WF, Ricci JA, Chee E, Hahn SR, Morganstein D. Cost of lost productive work time among US workers with depression. JAMA. 2003;289(23):3135-44.

12. Kessler RC, Akiskal HS, Ames M, Birnbaum H, Greenberg P, Hirschfeld RM, et al. Prevalence and effects of mood disorders on work performance in a nationally representative sample of U.S. workers. Am J Psychiatry. 2006;163(9):1561-8.

13. Rihmer Z. Prediction and prevention of suicide in bipolar disorders. Clin Neuropsychiatry. 2005;2(1):48-54.

14. Tondo L, Lepri B, Baldessarini RJ. Suicidal status during antidepressant treatment in 789 Sardinian patients with major affective disorder. Acta Psychiatr Scand. 2008;118(2):106-15.

15. Shabani A, Jolfaei AG, Vazmalaei HA, Ebrahimi AA, Naserbakht M. Suicidal attempt in bipolar disorder: low significance of comorbidity with opioid dependence. Iran J Psychiatry. 2009;4(2):74-8.

16. Murray CJ, Lopez AD. Evidence-based health policy-lessons from the Global Burden of Disease Study. Science. 1996;274(5288):740-3.

17. Gitlin MJ, Swendsen J, Heller TL, Hammen C. Relapse and impairment in bipolar disorder. Am J Psychiatry. 1995;152(11):1635-40.

18. Kogan JN, Otto MW, Bauer MS, Dennehy EB, Miklowitz DJ, Zhang HW, et al. Demographic and diagnostic characteristics of the first 1000 patients enrolled in the Systematic Treatment Enhancement Program for Bipolar Disorder (STEP-BD). Bipolar Disord. 2004;6(6):460-9.

19. Baek JH, Park DY, Choi J, Kim JS, Choi JS, Ha K, et al. Differences between bipolar I and bipolar II disorders in clinical features, comorbidity, and family history. J Affect Disord. 2011;131(1-3):59-67.

20. Leverich GS, Post RM. Life charting the course of bipolar disorder. In: Rush AJ editor. Current review of mood and anxiety disorders.. Philadelphia: Lippincott Williams and Wilkins; 1996. pp. 48-61.

21. Leverich GS, Post RM. Life charting of affective disorders. CNS Spectr. 1998;3:21-37.

22. Leverich GS, Nolen WA, Rush AJ, McElroy SL, Keck PE, Denicoff KD, et al. The Stanley Foundation Bipolar Treatment Outcome Network. I. Longitudinal methodology. JAffect Disord. 2001;67(1-3):33-44.

23. Kupfer DJ, Frank E, Grochocinski VJ, Cluss PA, Houck PR, Stapf DA Demographic and clinical characteristics of individuals in a bipolar disorder case registry.J Clin Psychiatry. 2002;63(2):120-5.

24. Shabani A, Jolfaei AG, Vazmalaei HA, Ebrahimi AA, Naserbakht M. Clinical and course indicators of bipolar disorder type I with and without opioid dependence. J Res Med Sci. 2010;15(1):20-6.

25. Ghanbari Jolfaei A, Shabani A. [A comparative study of prevalence for anxiety disorders in Bipolar I patients with or without opioid dependency.] . J Kermanshah Univ Med Sci. 2013;16(8):665-72.

26. Suppes T, Leverich GS, Keck PE, Nolen WA, Denicoff KD, Altshuler LL, et al. The Stanley Foundation Bipolar Treatment Outcome Network. II. Demographics and illness characteristics of the first 261 patients. J Affect Disord. 2001;67(1-3):45-59.

27. Lish JD, Dime-Meenan S, Whybrow PC, Price RA, Hirschfeld RM. The National Depressive and Manic-depressive Association (DMDA) survey of bipolar members.J Affect Disord. 1994;31(4):281-94.

28. Regier DA, Farmer ME, Rae DS, Myers JK, Kramer M, Robins LN, et al. One-month prevalence of mental disorders in the United States and sociodemographic characteristics: the Epidemiologic Catchment Area study. Acta Psychiatr Scand. 1993;88(1):35-47.

29. Jablensky A, Hugler H, Von Cranach M, Kalinov K. Kraepelin revisited: a reassessment and statistical analysis of dementia praecox and manic-depressive insanity in 1908. Psychol Med. 1993;23(4):843-58.

30. Rasanen P, Tiihonen J, Hakko H. The incidence and onset-age of 


\section{GhanbariJolfaei A et al.}

hospitalized bipolar affective disorder in Finland. J Affect Disord. 1998;48(1):63-8.

31. Comtois KA, Russo JE, Roy-Byrne P, Ries RK. Clinicians' assess- ments of bipolar disorder and substance abuse as predictors of suicidal behavior in acutely hospitalized psychiatric inpatients. Biol Psychiatry. 2004;56(10):757-63. 